tionally renowned surely should be in the Canadian Medical Hall of Fame."

What will it take to award Dr. Griffith a deserved place in the Canadian Medical Hall of Fame?

Maria Pacelli

Montreal, Quebec

\section{Visible bubbles in the internal jugular vein during carotid endarterectomy}

To the Editor:

We observed bubbles in the internal jugular vein (IJV) of a patient during right carotid endarterectomy under general anesthesia (induction: $150 \mu \mathrm{g}$ fentanyl, $200 \mathrm{mg}$ thiopental, $50 \mathrm{mg}$ rocuronium: maintenance: $\mathrm{O}_{2}$ $40 \% / \mathrm{N}_{2} \mathrm{O} \quad 60 \%$, isoflurane $\left.0.5-1.0 \%\right)$. Catheters were inserted into the radial artery (\#20G) and vein (\#18G) in the left arm. The patient was positioned supine, head elevated $30^{\circ}$ and turned to the left. During surgery, a coalescence of small bubbles was observed throughout the exposed portion of the IJV. After documentation with Doppler they were aspirated (\#25G needle). The patient remained hemodynamically stable without change in pulse oximetry or $\mathrm{P}_{\mathrm{ET}} \mathrm{CO}_{2}$. The postoperative course was uneventful. In a subsequent series of carotid endarterectomies under general anesthesia (catheters in extremity side opposite to surgery), bubbles were observed in the 12th consecutive patient (incidence $1 / 12(8 \%)-2 / 13(15 \%))$. The intra- and postoperative course of this patient was clinically unremarkable.

Bubbles observed in the IJV in $2 / 13$ consecutive patients undergoing carotid endarterectomy are similar to those described following radical neck dissection (incidence: $42 \%$ ). ${ }^{1}$ Air embolism may occur when the surgical site is above the right atrium, with venous pressure at the incision site below atmospheric pressure, and air is entrained into the incised veins or venules. ${ }^{2-4}$ This may occur during carotid endarterectomy with the head moderately elevated. Alternatively, air may have been introduced via the catheters. ${ }^{5}$ It is unclear whether this phenomenon is a benign, albeit curious, event or a harbinger of a clinically important air embolism.

Chantal Hickey MDCM

Steven B. Backman MDCM PhD FRCPC

Oren Steinmetz MDCM FRCSC

Montréal, Québec

\section{REFERENCES}

1 Rice JH, Gonzalez RM. Large visible gas bubbles in the internal jugular vein: a common occurrence during supine radical neck surgery? J Clin Anesth 1992; 4: 21-4.

2 Palmon SC, Moore LE, Lundberg J, Toung T. Venous air embolism: a review. J Clin Anesth 1997; 9: 251-7.

3 Lowenwirt IP, Chi DS, Handwerker SM. Nonfatal venous air embolism during cesarean section: a case report and review of the literature. Obstet Gynecol Surv 1994; 49: 72-6.

4 Roe BB. Air embolism prevention. Ann Thorac Surg 1987; 44: 212-3.

5 Rubinstein D, Dangleis $K$, Damiano TR. Venous air emboli identified on head and neck CT scans. J

Comput Assist Tomogr 1996; 20: 559-62.

\section{Abdominal distension during transurethral resection of a bladder tumour}

To the Editor:

Several points deserve attention in Oyston's ${ }^{1}$ report of gastric distension during positive pressure ventilation through a laryngeal mask airway (LMA).

Peak airway pressure should be $<20 \mathrm{~cm}$ water if the patient's lungs are healthy, the LMA is correctly placed, depth of anesthesia and/or neuromuscular blockade are adequate and abdominal pressure is not increased. Peak airway pressure of $28 \mathrm{~cm}$ water with a tidal volume of $500 \mathrm{~mL}$ indicates partial airway obstruction and should prompt a search for possible causes. Auscultation of the epigastrium would have demonstrated gastric insufflation and the need to remove and reposition the LMA correctly before gross gastric distension occurred. A tympanitic percussion note would distinguish abdominal distension due to gastric insufflation from leakage of fluid from a ruptured bladder.

On the rare occasions when gastric decompression is required, we ventilate with $100 \%$ oxygen, remove the LMA and pass a gastric tube through a Williams airway intubator (Anesthesia Associates, San Marcos CA) to aspirate air and/or gastric fluid. We then remove both devices, reinsert the LMA and confirm its correct position. Although one of us helped to design the airway intubator for blind tracheal intubation, ${ }^{2}$ we find that it is also an excellent conduit for an oral gastric tube.

The size 3 LMA is now considered too small for positive pressure in adult females. It may fit poorly around the laryngeal inlet, or pass into the proximal esophagus. ${ }^{3}$ Current European practice is to use size 4 for adult women and size 5 for adult men when positive pressure ventilation is used. . $^{3,4}$ 
J. Roger Maltby MB FRCA FRCPC

Michel T. Beriault MD FRCPC

Calgary, Alberta

\section{REFERENCES}

1 Oyston J. Abdominal distension during transurethral resection of a bladder tumour (Letter). Can J Anaesth 1998; 86: 1134.

2 Williams RT, Maltby JR. Airway intubator (Letter). Anesth Analg 1982; 61: 309.

3 Brimacombe JR, Barry AM, Campbell RC, Verghese $C$. Selection of the proper size of laryngeal mask airway in adults (Letter). Anesth Analg 1996; 83: 663-4.

4 Voyagis GS, Batzioulis PG, Secha-Doussaitou PN. Selection of the proper size of laryngeal mask airway in adults (Letter). Anesth Analg 1996; 83: 663-4.

\section{Essential oil to promote inhalational induction in children}

To the Editor:

None of the volatile anesthetic agents have pleasant odours. We evaluated the use of essential oil of sweet orange to obscure the odour of sevoflurane and make it pleasant to inhale. One hundred and twenty children ASA 1 or 2 of both sexes aged between five and $14 \mathrm{yr}$ undergoing dental extraction participated in a randomised double blind trial.

A standard technique consisting of sevoflurane in $50 \% \mathrm{O}_{2}$ and $\mathrm{N}_{2} \mathrm{O}$ was used. In 60 children, the breathing filter was impregnanted with four drops of essential oil. After two breaths of gas mixture with sevoflurane $1 \%$ the child was asked to rate the odour of anesthetic vapour as pleasant, acceptable, unpleasant and horrid. Sevoflurane concentration was then rapidly increased to $8 \%$. Before discharge the children were asked to grade the acceptability of induction and whether they would like a similar technique used again in future.

Smooth induction was achieved in $85 \%$ of children in the essential oil group and the grading of anesthetic vapour odour was more favourable in this group $(72 \%$ vs $23 \%, P<0.05)$ as was acceptability of induction $(P<0.05)$. Children in the essential oil group were more likely to prefer a similar anesthetic technique in future $(82 \%$ ps $55 \%, P<0.05)$.

We have also used essential oil with halothane induction with excellent results.

\section{S. Mehta}

D.N. Stone

H.E. Whitehead

Burnley, England 